\title{
The determinants of intra-firm diffusion process of ICT: theoretical sources and empirical evidence from Catalan firms
}

\author{
Adel Ben Youssef ${ }^{\text {a }}$ \\ (GREDEG \& University Nice Sophia-Antipolis) \\ \& \\ David Castillo Merino ${ }^{\mathrm{b}}$ \\ (UOC Barcelona) \\ $\boldsymbol{\&}$ \\ Walid Hadhri ${ }^{\mathrm{c}}$ \\ (ADIS University of Paris Sud \\ \& UAQUAP University of Tunis)
}

\begin{abstract}
The analysis of the main determinants of intra-firm diffusion of digital technologies is becoming in the focus of attention. However, there is a lack of empirical research, particularly in Europe. This paper proposes a specific approach to modelling intra-firm diffusion process by combining the well-established models of technological diffusion with organizational and networking complementarities view and epidemic evolutionary approaches. Our investigation is based upon a survey conducted in 2003 for 2038 enterprises by the Catalan government. Three econometric models are then tested. The first one is an ordered probit model where we test the probability of ICT adoption by firms. Secondly, we built a general model explaining intra-firm diffusion of ICT according to some specific tools as well as to different business uses of these digital technologies. Our results confirm the well-established literature. Thus, the main conclusion of this paper is that inter-firms ICT diffusion (i.e. investment in digital equipment) and ICT depth of adoption (i.e. spread of efficient digital uses), have different determinants, although they share some common traits based on the existence of complementary effects between digital technologies, innovation, organizational structure and workers skills within a firm.
\end{abstract}

Keywords: Intra-firm diffusion of innovation, ICT adoption, ICT uses, Probit Model, Depth of technology adoption.

JEL Classification: L21, O31, O33

\footnotetext{
a adel.ben-youssef@unice.fr

b dcastillo@uoc.edu

c walid.hadhri@u-psud.fr
} 


\section{Introduction}

The potential of Information and Communication Technologies usages in business is a well-covered topic during the last decade. Since ICTs are considered as General Purposes Technologies (Bresnahan and Trajtenberg, 1995, Antonelli 2003), they are shaping the internal organization of firms, their boundaries and also their productivity and performance. International literature gives empirical evidence that adopting a new technology influences firms' productivity rates in the short and long term. Short-term productivity losses may affect the decision process of adopting a new technology. In fact, it involves three main decisions: i) whether to adopt or not, ii) the replacement speed of old technology with new one, and iii) the extent to which the capabilities of the new technology will be exploited by a firm, which is usually known as "depth of adoption" (Astebro, 2004).

At least three views of this dynamics are expressed in economic theory. The first one is known as the non-equilibrium theory and is related to the seminal work of Mansfield (1963). Firms' usage dynamics follows an S shaped curve depending on time. Epidemic models (non equilibrium) are in general presented as the main explanation of this dynamics. The second one is known by the equilibrium theory (Battesti and Stoneman, 2003 and 2005). The adoption and the usage of the technology depend on the trade off between the cost and the benefits of additional usage. Since then there's no need for an S curve describing the usage over time. The patterns of usage are random depending on the opportunity costs of the usage. Finally and recently, Battesti and Stoneman 2009 have tried to link these two views by supposing that in an earlier stage of technology diffusion patterns follow the evolutionary dynamics (epidemic effect) and then when the technology is generalised and adopted, the equilibrium view is the good one. Recently, an empirical literature have tried to confirm this view by examining these dynamics in different settings (Bocquet and Brossard (2007) in France, Battestiti and Stoneman (2005) in Italy, Hollenstein, (2004) in Switzerland, Ben Youssef et al. (2011) in Tunisia...)

The objective of our study is to contribute to a better understanding of the determinants and patterns of ICT intra-firm diffusion by adapting Bocquet and Brossard (2007) approach and testing it using a single year -2003- cross section data set on the intrafirm diffusion of digital technologies in Catalan companies. In fact, in 2003 the adoption of ICT by Catalan firms was important however the usage is sub-optimal. By separating the dynamics of usage and adoption we will show how the two views are valid. Our paper aims also to verify the standard effects of technology adoption on the extent of ICT depth of adoption. Hence, we focus on firm's size, internal organization, absorptive capacity, cooperation and innovation. The main contribution is to verify how standard arguments for ICT adoption behaviour work in the context of Catalan firms in 2003 and highlighting the difference between digital technologies adoption and usage patterns.

In order to reach these objectives, our paper is divided into five sections. Section one summarizes the main findings in the economic theory related to intra-firm diffusion. Section two explains how data was collected and the theoretical model used. Section three identifies the main explanatory variables and specifies the empirical models. Section four discusses the results and the findings. Section five concludes. 


\section{The intra-firm diffusion of ICT literature review}

The intra-firm diffusion of ICT is nowadays in the centre of a fruitful international discussion, focused on a theoretical analysis of the determinants of the digital technologies diffusion process. In other words, several contributions are trying to identify the diffusion pattern and the main factors that may explain it. At the same time, an important effort is made in order to obtain empirical results from diverse theoretical approaches. This diffusion process of a new technology within a firm can be explained in the light of the depth of adoption of ICT concept. This construct can be defined as the extent to which a firm is able to exploit an innovation's potential technological capabilities (Astebro, 2004).

The majority of the existent diffusion literature (Stoneman, 2001) is mainly concerned with inter-firm diffusion. However, there is an increasing number of recent papers proposing approaches to modelling the intra-firm diffusion of a new technology (Battisti and Stoneman, 2003, 2005) as well as focusing on giving empirical evidence on this phenomenon, particularly on the diffusion of digital technologies within a firm (Bocquet and Brossard, 2007; Hollenstein, 2004. As Battisti and Stoneman (2003) state the inter-firm effect (i.e. the time profile of the number of firms using the technology) is more important in the early stages, while the intra-firm effect (i.e. the time profile of the extent of use by individual firms) more important in the later stages of the whole diffusion process.

Our data about Catalan companies gives support to this assumption. There is a great consensus in fixing the middle of the nineties (as in other developed economies) as the starting point of a general diffusion of information and communication technologies among industries for business uses in Catalonia ${ }^{\mathrm{d}}$. After a decade of digitalization, it can be confirmed that the adoption of digital technologies among Catalan firms was a fact ${ }^{\mathrm{e}}$. But if we look at digital uses by firms, the picture appears to be quite opposite. ICT were a basic work tool for just 15.6 per cent of Catalan companies, a statistic that gives us an idea of this early stage of implementation of the digital business in the Catalan economy, being the main uses management, administration and accounting tasks, and obtaining information ${ }^{\mathrm{f}}$.

\footnotetext{
${ }^{\mathrm{d}}$ As it will be explained in Section 4, the survey's sample contains 2,038 Catalan companies, being it significant in terms of size (number of employees - computing also micro-companies, with less than 10 employees) and industry.

e most of Catalan companies, 93.2per cent, used cell phones in 2003, regardless of the size of the firm, 97.3per cent had a computer, 90.9per cent had an Internet connection (67.0per cent of firms connected to the Internet and 60.9per cent of Catalan companies were connected to the Internet via an ADSL connection), and 87.4per cent of companies have e-mail. Among the reasons that companies gave for not having a website or e-mail - that is, the fact of not using the Internet as a possible channel to interact directly with suppliers and customers - it should be highlighted that the main reason was that they do not need it. In fact, 77.4per cent of companies that had neither website nor e-mail gave as a reason for not having them, that they do not need them. Other reasons - such as still being in the construction phase or the lack of finance - were cited by 11.0per cent and 9.4per cent of Catalan companies, respectively.

${ }^{\mathrm{f}}$ The 44.4per cent of companies mention these tasks, compared to other options, such as principal digital uses. Next, 29.3per cent of Catalan companies declared using digital technologies, especially the Internet, to obtain information, while an additional 27.4per cent employ it in their relationship with customers and suppliers. Communication is a fourth significant element. This use was cited by 23.4 per cent of Catalan firms. Therefore, at first sight, Catalan companies used digital technologies in production to become more efficient in internal administrative tasks and to improve their external relations through the communication, particularly with the customers in general, with the two external agents most directly linked to the business activity: customers and suppliers.
} 
These empirical evidence may question the epidemic effects (Mansfield, 1963) approach as the solely theory able to explain determinants of ICT uses diffusion in companies. As it can be deduced from this data description, inter-firm diffusion of digital technologies (measured here as ICT adoption) may be identified as a previous step to a depth of adoption stage. In fact, it can be said that 2003 conforms to an early stage in terms of the diffusion of ICT uses within Catalan firms.

Together with epidemic effects, rank, stock and order effects are the main and widely accepted facts concerning the explanation of intra-firm diffusion of a new technology (Karshenas and Stoneman, 1993). As it has been outlined by Battisti and Stoneman (2005), it is difficult to see relevance for an order effect on the intra-firm diffusion process, as any order effects may be internalised by a firm. Thus, our general framework of the "diffusion" approaches relies on epidemic, rank and stock effects.

(a) Epidemic effects explain the intra-firm diffusion process as the result of risk reduction of the depth of adoption over time (Mansfield, 1961, 1963). The main predictions of this type of models are: (i) the level of intra-firm diffusion is a growth function of time since first adoption by the firm, (ii) the depth of adoption follows a logistic S-shaped path increasing with time as use reduces the risk of adoption, and (iii) different diffusion paths for different firms and technologies reflect diverse levels of adoption profitability and initial risk levels (Battisti and Stoneman, 2003). Thus, epidemic models consider that the diffusion of a new technology requires the spreading of information about efficient uses of a new technology (Bocquet and Brossard, 2007). Battisti and Stoneman (2003, 2005) have shown that epidemic effects are not empirically significant to explain intra-firm diffusion processes. Thus, if these effects have any incidence on this process, it is due to the development of a technological absorption capacity within the firm. Following evolutionary approaches (Hanna and Freeman, 1989), this particular interpretation of epidemic models will lead to a connection between human capital and the diffusion of ICT uses by firms. We use here only those variables that can be understood as a proxy of human capital. The first set of variables is higher education degree of managers and workers. Educational level attainment is a factor that may influence digital technologies investment and use, as it conditions managers and workers' vision towards new technologies, which also depends on their own convictions. However, the importance of education is obvious, since new technologies require high-skilled workers. Furthermore, we try to analyse whether the fact that workers are enrolled in training programmes has an effect on ICT uses. The second variable is the average age of managers and workers. These variables can also give an idea of the effect of workforce experience on ICT usage. Experience is also summarized in a last variable defined as the average wages in a firm. We suppose here that human capital is not depreciating and age summarizes experience and learning. Then, the stock of "human capital" is approximated by these variables. The absorptive capacity effect refers also to the capability of a firm to develop its own mix of inputs and to adapt technologies to productive uses. Therefore, we use training inside the firm and employees and managers training as indicators of the ability to develop and use these technologies.

(b) Rank effects link with a benefit function approach and result from the fact of firms' differences in terms of returns on technology investment. The trade-off between expected benefits and costs from a technology adoption leads to consider sunk costs as well as costs spreading among products' incomes as critical factors to explain the diffusion of technology uses. Under this view, the most important effect summarizing the depth of adoption is firm's size. Different explanations are given in order to justify why large firms are more able to 
adopt and use new technologies (Fabiani et al., 2005; Morgan et al., 2006; Thong, 1999). Generally small firms rather easily show a daily use of digital technologies, but they need to be assisted to reach the more efficient uses. Therefore, the larger a company is the wider is the depth of ICT adoption and use. In our estimation, we took into account firms' size by the logarithm of the number of workers employed.

(c) Stock effects results from the evidence that low ICT uses may be the optimal choice for some firms, as marginal benefits, as well as productivity, tend to decrease after a new technology adoption. This situation leads to an increase of the uncertainty about the impact of raising intensity of digital uses on future benefits. This effect may be identified comparing different intensity uses related to diverse cost and benefit functions. As we have available a cross-section database, time dimension can not be considered in our model and, therefore, stock effects will not be distinguished from rank effects (Bocquet and Brossard, 2007). This is the main reason why this type of effects will not be measured and estimated here.

In addition to epidemic and "diffusion" effects, the ICT complementarities approach is a demonstrated effect on the explanation of digital spreading within a firm ((Bresnahan et al., 2002; Cristini et al., 2003). There is a mutually beneficial relationship between organisational change and ICT investments. Digital technologies is a key element to facilitate new organisational practices, such as lean production, team-working, more decentralization in strategic decision making activities, or a closer interaction with customers and providers of intermediate inputs. Therefore, ICT availability and usage increase firms' capacity to adapt their organisational structure to these new network requirements. At the same time, efficient ICT uses by firms require some specific organisational changes in order to maximize the exploitation of their technological capabilities. How ICT and organisational change are combined within a firm will determine the efficiency level achieved and, therefore, the degree of productivity gains. Firm-level organisational change can take many forms, but the general form can be classified into two broad systems (Murphy, 2002):

(d) Organizational effects explain that the extents at which ICT are used within a firm depends on its organizational design and its management practices. Since digital technologies are "network" technologies they are more efficient in a decentralized setting. They fit well with the connectivity effects arising from belonging to a group of companies and with the external links of importer firms. The variable "Belonging to a group", which indicates whether a firm belongs to a group or not, anticipates advantages from improving external relationships and coordination with others firms of its group, which cannot be neglected.

In addition, labour management practices connect firms' organization with ICT through new management practices and employees' schemes. In this sense, previous studies (Milgrom and Roberts, 1992; Osterman, 2000; Foss et al., 2007) have demonstrated that the interaction among decision-makers and executives are creating less hierarchical structures. Moreover, the transition from hierarchical structures towards more decentralized ones, in which knowledge and the power of decision-making are clearly imbricated is very useful to understand how the organization solves its problems of coordination, motivation and incentives. Therefore, the type of workforce control applied by the company is a critical variable for a better understanding of a firm's technological diffusion process. Digital technologies induce new forms of indirect employees control or supervision (to be reachable constantly), which are replacing the traditional forms of direct control based on a hierarchical supervision (Acemoglu and Newman, 2002). ICT, thus, tend to replace modes of control of the employees based on the input (attendance time in the company, direct or visual monitoring 
by a superior) by modes of control based on different measures of output or performance (objectives to be filled, times to be respected, answer brought to a request...). The variable "control by objectives or result", as an indication of the adoption of new organizational design, is represented here by a variable explaining if the firm has adopted a control based on objectives or results within its organization or not.

(e) Network effects results from the own nature of digital technologies. ICT are network technologies. Thus, we expect a positive correlation for importer firms. We also consider the number of customers and the number of providers as factors, which can influence ICT adoption and use. This fact should tend to increase the probability of integration in a broader network and thus the probability of ICT usage by firms. We try to approximate here the connectivity of a firm by the number of the relationships (customers, suppliers, importers and plants). We expect a positive effect between the connectivity of a firm and the ICT adoption process. In other words, if size gives us the internal dimension of a firm's connectivity, the above mentioned factors give us the external dimension of this connectivity. Within network approach, the effect of the sector affiliation on ICT adoption can also be considered. The economic sector should also constitute an important factor of adoption as it reflects production and organisational logics. Thus, we distinguished in our study between firms belonging to the information sector from the others.

Furthermore, network effects can be also understood as a firm's cooperation effort to innovate. Cooperation needs coordination and communication technologies. In this sense, the more the firm is engaged in cooperation the more it uses ICT. So in our explanatory variables, we consider if a firm is cooperating with others institutions, such as others firms, universities, research and innovation centers, with competitors, with suppliers, with customers, or not. We also try to explain the difference on ICT use and adoption between innovative and not noninnovative firms and in particular between those firms using digital technologies to innovate and the others. Complementary investments in innovation are essential for the advantages of the ICT adoption to appear; therefore, firms' investment in digital technologies will impact performance only if it is accompanied by a set of organizational changes and complementary investments, otherwise the economic impact of ICT will be limited (OECD, 2004). An innovative company reaches, through innovation, new market opportunities, either because innovation will have enabled it to reduce costs, or because new products or services will answer better the demand requirements, while making it possible to the customers to profit from more complete services, adapted better to the request or more respectful of the environment. The use and the diffusion of the ICT facilitate and support the innovation for all the companies. Indeed, the innovating firm had more probability of being well equipped of ICT. ICT allows trial and errors without costs (Learning before doing). At the same time, ICT allows the generalization of the exploration- exploitation process and the involvement of nonmanager workers (Bellon et al. $2006 \&$ 2007). These facts increase the speed of the innovation. Three variables are used in our paper; innovation led by ICT, cooperation with other firms through ICT and whether the firm is innovative or not.

ICT diffusion is a complex issue as digital technologies include a huge number of different tools and devices (computers, Internet, LAN/WAN, EDI systems, Web site, CRM systems, etc.) which allow general and specific uses. It is a fact that firms won't necessarily use of all them and that ICT tools uses won't be at the same time. Therefore, it is difficult to define a measure of digital uses within a firm. Given that we aim to identify determinants of 
different ICT diffusion patterns, we propose to use a twofold measurement system here ${ }^{\mathrm{g}}$ : i) a first one that consider specific ICT tools (such as CRM, EIS or ERP) adopted by a firm (as they are specific and complex, we assume that a firm will only adopt them if an "appropriate" use has been planned before adoption); ii) and a second measure that relies on different business uses of digital technologies that have been declared by firms.

\section{Sample, data description and econometric models}

\subsection{Data}

The analysis is based on the data of a survey conducted between January and May 2003 on the firms developing their activity in Catalonia. Its general objective is to analyze the transformation of the strategy and the organization of the companies linked to the use of information and communication technologies (ICT). The survey has been carried out by a questionnaire, consisting of a face-to-face interview of one-hour duration, on a representative sample of 2038 Catalan firms. The interviews, held with entrepreneurs or company directors who have a global vision of the whole activity, were generally well received and the collaboration of the interviewed was high. In addition, the questionnaire information was completed with economic and financial information available to the general public in the Registre Mercantil (Mercantile Register), obtained through the SABI program.

The questionnaire yielded data, for all firms, on the ICT equipments, such as Internet, E-mail, Intranet, LAN/WAN/..., the objective pursued by using ICT, such as, Information, Communication, Administration...and many other variables which may also serve as determinants of ICT adoption

The data set contains information on firm's characteristics such as size, industry affiliation, number of customers, number of providers, human capital composition and financials characteristics.

\subsection{The models}

In order to study the factors influencing the intra-firms diffusion of ICT in Catalan firms, we use an ordered probit econometric model. The aim of the model is to determine the effect of different factors on the probability of the ICT adoption and use by the firm, i.e. age, size and networks effects, firm's organizational structure, absorptive capacity and human capital effect and the innovation and cooperation effect. Indeed, this method makes it possible to examine the exerted influence by series of factors on a multinomial ordered variable.

The basic variables of our study are binary and qualitative (they take the value one if the firm uses an ICT tool and value zero if not). Firms' answers give us the information on whether they adopt or use a particular technology or a tool of communication or not. For example, a firm indicates if it chooses the use of Intranet or not. Since we have various types of binary variables, they are gathered, then, in different types of scores, in order to formulate a total score of adoption and a total score of ICT use. This gives us the multinomial character of this distribution (because it is composed of various methods) and the ordered character (because it is deduced starting from other binary variables).

\footnotetext{
${ }^{\mathrm{g}}$ This measurement system will be developed in Section 5 .
} 
From these particular hypotheses, we use ordered probit models. Indeed, the explained variable ranges from one to 18 for the adoption score and from one to 11 for the usage score. These variables are thus discrete and ordinate. A probit multinomial model would thus neglect the ordinality of the dependent variable while a linear regression, on an opposite sense, would take into account the difference between indices three and four in the same way that the difference between indices one and two, whereas this corresponds only to one classification. In these two cases, the estimators would be thus biased (Greene 2000; Thomas, 2000).

The models commonly used for this type of variables are thus the ordered logit and probit models. These models are founded on the estimation of a continuous latent variable, subjacent with the subscripted variable of interest. In an ordered probit model, the residual associated with this latent variable is supposed to follow a normal distribution.

Indeed, this method makes it possible to study the influence exerted by series of factors on a multinomial ordered variable (Greene, 2000; Thomas, 2000). The ordered probit models are generally based on probability. The latent model is similar to that of a binomial probit.

$y_{i}^{*}=\beta x_{i}+\varepsilon_{i}$

Where $y_{i}^{*}$ is unobserved, continuous and latent measurement of ICT use, $x_{i}$ a vector of endogenous variables, $\beta$ the vector of the parameters and, $\varepsilon_{i}$ the residual error, which follows a normal distribution. In the case of the probit multinomial ordered, one observes:

$$
y_{i}=j \quad \text { if } \quad c_{j}<y_{i}^{*}<c_{j+i}
$$

Where $j=0,1, J$ represent the various methods of the endogenous variable. The observed coded variable, $y_{i}$ are determined by the following model:

$$
\begin{array}{rlrl}
y_{i} & =0 \quad \text { if } & -\infty<y_{i}^{*}<\mu_{1}, \\
& =1 \quad \text { if } & \mu_{1}<y_{i}^{*}<\mu_{2}, \\
& =2 \quad \text { if } & \mu_{2}<y_{i}^{*}<\mu_{3}, \\
& \vdots & & \\
& =J \quad \text { if } & \mu_{J-1}<y_{i}^{*}<\mu_{J},
\end{array}
$$

Where $\mu_{k}$ is an unknown parameter that must be estimated with the vector $\beta$.

The estimation of the model enables us to obtain the probabilities of realization of each index of the dependent variable. These probabilities are given by: 


$$
\begin{aligned}
& \operatorname{Pr} o b\left(y_{i}=0\right)=\phi\left(-\beta^{\prime} x_{i}\right) \\
& \operatorname{Pr} o b\left(y_{i}=1\right)=\phi\left(\mu_{1}-\beta^{\prime} x_{i}\right) \\
& \operatorname{Pr} o b\left(y_{i}=2\right)=\phi\left(\mu_{2}-\beta^{\prime} x_{i}\right)-\phi\left(\mu_{1}-\beta^{\prime} x_{i}\right) \\
& \operatorname{Pr} o b\left(y_{i}=3\right)=\phi\left(\mu_{3}-\beta^{\prime} x_{i}\right)-\phi\left(\mu_{2}-\beta^{\prime} x_{i}\right) \\
& \quad \vdots \\
& \operatorname{Pr} o b\left(y_{i}=J\right)=1-\phi\left(\mu_{J-1}-\beta^{\prime} x_{i}\right)
\end{aligned}
$$

With $\phi$ represent the normal law function distribution. The adjustment of the model is done by the Maximum likelihood estimation (Maddala and Flores, 2001):

$$
L=\prod_{i=1}^{N} \prod_{j=0}^{J} F_{i j}(x, \beta)^{y_{i j}}
$$

Let us note that the marginal effects of the explanatory variables $x_{i}$ on the probabilities are not equal to the coefficients. Thus, only the sign of the coefficient will be interpreted here and not its value. We try to model first the intensity of equipment or adoption of ICT and second the intensity of usage of various ICT tools.

\section{The variables}

\subsection{Dependant variables}

In our study we considered three models for three different dependant variables. Our dependent variables are obtained starting from the calculation of a total score of equipment and uses, which is obtained by summing two sub-scores (General Equipment and Specific Equipment), and a score of ICT uses.

\begin{tabular}{ll}
\hline \hline \multicolumn{1}{c}{ Variable } & \multicolumn{1}{c}{ Definition } \\
\hline \hline ( General equipment & Number of ICT general equipment adopted by the firm in 2003 \\
(2) Specific equipment & Number of ICT specific equipment adopted by the firm in 2003 \\
3 ICT usage & Number of ICT equipment already in use by the firm in 2003 \\
\hline \hline
\end{tabular}

Table 1. Definition of the dependant variables

\section{A - Variables measuring ICT tools adopted by firms}

The first variable (score of general equipment: Model 1) gather the basic or general purpose ICT tools that the firm has, such as: 1- Mobile Phone, 2- Computers, 3- Internet, 4LAN/WAN, 5- EDI, 6- Web site, 7- E-mail, 8- Intranet, 9- Firewall or antivirus (either nine types of use).

The second variable (score of specific equipment: Model 2) gather the specific ICT tools for each firm, such as: 1- Information processing system of production planning, 2Information processing system of production planning to providers, 3- Information processing system of production planning to distributors, 4- CRM, 5- operational system of accounting 
and invoicing, 6- system of payment by ICT tools, 7- system or control program of data or exploitation of information, 8- EIS and 9- ERP (either nine types of use).

Each variable is presented, therefore, as follows:

$$
\left\{\begin{array}{c}
y_{i}=0 \quad \text { if } \quad \text { zero equipment } \\
y_{i}=1 \quad \text { if } \quad \text { one equipment } \\
y_{i}=2 \quad \text { if } \quad \text { two equipments } \\
\quad \vdots
\end{array}\right.
$$

With $\mathrm{n}=9$ for variables score General Equipment, $\mathrm{n}=9$ for the variable score Specific Equipment and $\mathrm{N}=18$ for the Total Score variable (Score of adoption).

$y_{i}$ represent the dependant variable of the adoption of ICT by the firm $i$. This variable will be estimated by different explanatory variables $\left(X_{i}\right)$.

\section{B-Variables measuring intensity of ICT business uses}

In this section, we chose to distinguish between the uses of the ICT, not according to the tool used (Internet, Computers, EDI...), but according to the real usage expressed by the firm via their answers concerning usage. In order to obtain this variable we gathered eleven purposes of ICT use by the firms, such as: Communication, Information, Management, ecommerce, e-mail... Every firm has a score between zero and 11 .

The variable used here (score of ICT uses: Model 3) is, also, an ordered polytomic variable characterizing the finality of the ICT usages by the firm. It gathers the uses which meet specific needs for the company, such as: 1- Communication, 2- Communication with costumers and providers, 3- Information via Internet, 4- E-mail, 5- E-banking, 6- Web Page and Online Marketing, 7- Internal communication, 8- Management, administration, Accounting, 9- Basic tool in work/tasks, 10- E-commerce and 11- e-procurement (either 11 types of use).

Therefore this variable is presented as follows:

$$
\left\{\begin{aligned}
y_{i}=0 \quad \text { if } \quad \text { zero usage } \\
y_{i}=1 \quad \text { if } \quad \text { one usage } \\
y_{i}=2 \quad \text { if } \quad \text { two usages } \\
\vdots \\
y_{i}=11 \quad \text { if } \quad 11 \text { usages }
\end{aligned}\right.
$$

$y_{i}$ represent the dependant variable which summarizes the intensity of ICT usage by the firm $i$. We test the estimation in function of the same explanatory variables $\left(X_{i}\right)$ of the first model.

Explanatory variables are summarized in table 2, as follows: 


\begin{tabular}{|c|c|}
\hline Explanatory variables & Definition \\
\hline \multicolumn{2}{|l|}{ I. Epidemic effects } \\
\hline HE degree of managers & $\begin{array}{l}\text { Dummy variable: equal to } 1 \text { if the director has a university level } \\
\text { and } 0 \text { so not. }\end{array}$ \\
\hline Average age of managers & The age average of the directors \\
\hline HE degree of workers & $\begin{array}{l}\text { Dummy variable: equal to } 1 \text { if the employees have a university } \\
\text { degree and } 0 \text { if not. }\end{array}$ \\
\hline Average age of workers & The average age of the employees \\
\hline Average wage & The logarithm of the average wage in the firm \\
\hline \multicolumn{2}{|l|}{ II. Rank effects } \\
\hline Age & The age of the firm \\
\hline Size & The logarithm of the number of establishment's workers. \\
\hline \multicolumn{2}{|l|}{ III.Learning effect } \\
\hline Workers training & $\begin{array}{l}\text { Dummy variable: equal to } 1 \text { if the employees are implied in } \\
\text { training programs }\end{array}$ \\
\hline \multicolumn{2}{|c|}{ IV. Organizational effects } \\
\hline Control by objective or result & $\begin{array}{l}\text { Dummy variable: equal to } 1 \text { if the firm admits a control of } \\
\text { payment by objective or result and } 0 \text { if not }\end{array}$ \\
\hline Belonging to a group & $\begin{array}{l}\text { Dummy variable: equal to } 1 \text { if the firm belong a group and } 0 \text { if } \\
\text { not }\end{array}$ \\
\hline \multicolumn{2}{|l|}{ V. Network effect } \\
\hline Importer Firm & $\begin{array}{l}\text { Dummy variable: equal to } 1 \text { if the firm is an importer and } 0 \text { if } \\
\text { not }\end{array}$ \\
\hline Number of customers & The logarithm of the number of the customers of the firm \\
\hline Number of providers & The logarithm of the number of providers of the firm \\
\hline Information industry sector & $\begin{array}{l}\text { Dummy variable: equal to } 1 \text { if the firm belongs to the sector of } \\
\text { information and } 0 \text { if not }\end{array}$ \\
\hline Innovation process led by ICT use & $\begin{array}{l}\text { Dummy variable: equal to } 1 \text { if the firm starts its innovation } \\
\text { process by the use of ICT and } 0 \text { if not. }\end{array}$ \\
\hline Innovative Firm & $\begin{array}{l}\text { Dummy variable: equal to } 1 \text { if the firm is innovating and } 0 \text { if } \\
\text { not. }\end{array}$ \\
\hline $\begin{array}{l}\text { Firm which cooperates with other firms/ } \\
\text { institutions }\end{array}$ & $\begin{array}{l}\text { Dummy variable: equal to } 1 \text { if the firm has a co-operation with } \\
\text { other companies or institutions }\end{array}$ \\
\hline
\end{tabular}

Table 2. Description of the explanatory variables

\section{Determinants of intra-firm ICT diffusion in Catalan firms}

This section presents the empirical results of a probit ordered model of the determinants of ICT adoption and use by Catalans firms. These determinants are gathered according to the different approaches quoted above.

In order to characterize the adoption process we divide our investigation in three different models. Model 1 estimates the adoption of General Purpose technologies'. Model 2 estimates the adoption of specific technologies, and model 3 estimates the intensity of different business uses of ICT.

\begin{tabular}{llll}
\hline \hline & & ICT diffusion score \\
\hline \hline Explanatory Variables & General & Specific & ICT uses \\
Model 1 & Model 2 & Model 3 \\
\hline
\end{tabular}




\begin{tabular}{|c|c|c|c|c|}
\hline \multicolumn{5}{|l|}{ I. Epidemic effects } \\
\hline HE degree of managers & $\begin{array}{l}\text { No } \\
\text { Yes }\end{array}$ & $\begin{array}{c}\text { Ref. } \\
0.3142 * * *\end{array}$ & $\begin{array}{c}\text { Ref. } \\
0.0422\end{array}$ & $\begin{array}{c}\text { Ref. } \\
0.1491 * *\end{array}$ \\
\hline Average age of managers & & $-0.0091 * *$ & -0.0049 & $-0.0054 *$ \\
\hline Average age of workers & & $-0.0134 * * *$ & $-0.0083 *$ & Ref. \\
\hline Average wage & & $0.4093 * * *$ & 0.0536 & $0.1868 * *$ \\
\hline \multicolumn{5}{|l|}{ II. Rank effects } \\
\hline Age & & -0.0044 & 0.0432 & $-0.0620 *$ \\
\hline Size & & $0.2553 * * *$ & $0.1482 * * *$ & $0.0613 * *$ \\
\hline \multicolumn{5}{|l|}{$\begin{array}{l}\text { III. Learning effect } \\
\end{array}$} \\
\hline Workers training & $\begin{array}{l}\mathrm{No} \\
\mathrm{Yes}\end{array}$ & $\begin{array}{c}\text { Ref. } \\
0.1982 * *\end{array}$ & $\begin{array}{c}\text { Ref. } \\
0.0629\end{array}$ & $\begin{array}{c}\text { Ref. } \\
0.0847\end{array}$ \\
\hline \multicolumn{5}{|c|}{ IV. Organizational effects } \\
\hline Belonging to a group & $\begin{array}{l}\text { No } \\
\text { Yes }\end{array}$ & $\begin{array}{l}\text { Ref. } \\
0.1739 * *\end{array}$ & $\begin{array}{c}\text { Ref. } \\
0.0201\end{array}$ & $\begin{array}{c}\text { Ref. } \\
0.0539\end{array}$ \\
\hline Control by objective or result & $\begin{array}{l}\text { No } \\
\text { Yes }\end{array}$ & $\begin{array}{l}\text { Ref. } \\
0.1361 * *\end{array}$ & $\begin{array}{l}\text { Ref. } \\
0.0949\end{array}$ & $\begin{array}{c}\text { Ref. } \\
-0.0280\end{array}$ \\
\hline \multicolumn{5}{|l|}{$\begin{array}{r}\text { V. Network effects } \\
\end{array}$} \\
\hline Importer Firm & $\begin{array}{l}\text { No } \\
\text { Yes }\end{array}$ & $\begin{array}{c}\text { Ref. } \\
0.2932 * * *\end{array}$ & $\begin{array}{c}\text { Ref. } \\
0.2927 * * *\end{array}$ & $\begin{array}{c}\text { Ref. } \\
0.2026 * * *\end{array}$ \\
\hline Number of customers & & $0.0575 * * *$ & 0.0009 & $0.0335 * * *$ \\
\hline Number of providers & & $0.05210 * *$ & 0.0318 & 0.0087 \\
\hline Information industry sector & $\begin{array}{l}\text { No } \\
\text { Yes }\end{array}$ & $\begin{array}{l}\text { Ref. } \\
0.1638 * *\end{array}$ & $\begin{array}{c}\text { Ref. } \\
0.0457\end{array}$ & $\begin{array}{c}\text { Ref. } \\
0.3330 * * *\end{array}$ \\
\hline Innovation process led by ICT use & $\begin{array}{l}\text { No } \\
\text { Yes }\end{array}$ & $\begin{array}{l}\text { Ref. } \\
0.2215^{* * *}\end{array}$ & $\begin{array}{c}\text { Ref. } \\
0.1508^{* *}\end{array}$ & $\begin{array}{c}\text { Ref. } \\
0.1763 * * *\end{array}$ \\
\hline Innovative Firm & $\begin{array}{l}\text { No } \\
\text { Yes }\end{array}$ & $\begin{array}{l}\text { Ref. } \\
0.3732 * * *\end{array}$ & $\begin{array}{l}\text { Ref. } \\
0.0958\end{array}$ & $\begin{array}{c}\text { Ref. } \\
0.2218 * * *\end{array}$ \\
\hline Firm which cooperate with & No & Ref. & Ref. & Ref. \\
\hline Other firms/ institutions & Yes & $0.1299 *$ & $0.1620^{* *}$ & $0.1083^{*}$ \\
\hline
\end{tabular}

Table 3. Determinants of ICT intra-firm diffusion

By observing all the explanatory variables, it can be outlined the importance of ICT complementarities approach and evolutionary models to improve the explanation of the main determinants of business' digitalization process. In fact, we have demonstrated that some particular organizational practices are critical on the early adoption stage, while network effects emerge contribute to explain the diffusion of ICT uses within a firm. Our results confirm the expected effects stated above. Let's see them step by step.

\section{Epidemic effects}

From an epidemic model point of view, we have demonstrated in this paper a positive contribution of managers' education attainment and workers profile. In fact, those firms with more qualified managers and younger workers are those showing a higher probability to use more digital technologies. In addition, managers and their profile (educational level, age, style of commandment, position towards ICT...) impact strongly the technology adoption process. Managers are the main responsible for the success of ICT introduction in small and medium firms.

In fact, higher education attainment by managers has a positive link with the probability of ICT adoption. Firms whose managers have attained higher education studies implement more rapidly these technologies since they are more likely to understand the aims of these technologies and more able to impact their collaborators. Since then, the degree of adoption of ICT in their companies is higher on average. 
Our results also show a negative relationship between the age of both, managers (with $\mathrm{p}<0,05)$ and workers $(\mathrm{p}<0,00)$ and the willingness of firms to adopt digital technologies. Therefore, it seems demonstrated that firms with younger workers, younger and highly qualified managers, and with workers following training programmes have a higher willingness to invest in digital technologies.

In terms of digital uses, we have found that the intensity of usage is positively correlated with the absorptive capacity of the firm. In our sample of Catalan firms, one notices that firms with managers having university degree attainment have higher intensity of use of the more important ICT. The use of digital technologies by managers is far from being uniform and shows disparities. However, the use of ICT increased for all the categories of age, even if the phenomenon seems to be a little faster in the young people of less than 30 years. The intensity of ICT uses by directors decreases with age, which is the case in our paper.

In addition to those factors, firm's efficiency plays an important role in the explanation of ICT adoption by firms. Moreover, the use of ICT is more important in those firms showing a higher level of average wages. Therefore, as much for digital equipment as that for use, ICT are mainly adopted and used by those companies with high-skilled workers.

The implementation of ICT requires mid-term, and sometimes short-term, specific competences within the firm especially those related to data processing and computer problem solving. We observe that the average wage in a firm has a positive effect on ICT equipment or adoption. Since wages are considered as an imperfect measure of workers' productivity leaded by their competencies and qualifications, this may allow us to interpret this correlation by a relationship between ICT adoption and qualifications. Therefore, it is important to note that ICT are more adopted by firms with higher levels of employees' skills.

\section{Rank effects}

Firstly, we verify a strong, positive and significant relationship between size and the probability of ICT adoption by a firm. As it was expected, there is a positive correlation between firm's size and ICT capital stock, showing the existence of scale economies for digital investment. Similar to industrial technologies, large firms have more incentives to adopt ICT, as they have the chance to spread adjustment costs over a more substantial output volume.

Firm' size has a positive and significant effect on the adoption of the two kinds of ICT equipments econometric models (General and Specific). This result is mainly due to two relevant facts: to the depth of technologies argument and to the importance of internal coordination and communication within the firm. This finding is also consistent with the evidence that larger firms are more likely to adopt digital technologies because they show lower levels of financial constraints.

Moreover, the size of the firm exerted a positive and significant effect on the intensity of use of ICT, like the case of the equipment. The intensity of use by a firm is positively correlated with its size. Our result confirms most of the well-established literature on this subject (OECD, 2004). 
In this sense, it is important to outline that firms' size and productivity levels have also in our ICT usage model a positive and significant effect on the explanation of the probability of digital technologies depth of adoption, but the relationship is weaker than in our ICT Equipment models. This means that the chance to obtain scale economies and firms' economic results seems not to be critical factors to explain the willingness and intensity of ICT use by a firm.

\section{Learning effect}

We have theoretically complemented epidemic effects with firms' technological absorption capacity based on learning, in the explanation of the intra-firm diffusion process. Our results also show a positive relation with firm's investment on workers training. The employees can acquire various qualification levels in ICT. These competences can be acquired by different ways that is to say by the various stages of conventional teaching in schools or universities or by a workplace specific training. This result is also confirmed in our estimation. Thus, it is found that firms with employees enrolled in training programs have more intensity of ICT uses. And it confirms Bresnahan et al. (2002 a \& b) virtuous circle between ICT uses and workers' skills, the positive effect of firms' networking structure on the depth of ICT adoption is complemented by the positive and significant contribution of human capital formation as determinants of economic digital uses by firms.

\section{Organization effects}

We have divided complementarities approach into two different classes: organizational practices and network effects.

As it was expected, we have found a positive and significant effect of new organizational practices, workers' skills and the existence of innovation policies on firms' willingness to invest in digital technologies.

Concerning organization, we have found that an organizational structure based on flexibility and decentralization on tasks execution and on the assessment of objectives reached lead to a higher probability of ICT adoption. It is interesting to note that network structure seems to be particularly appropriate for knowledge diffusion in all different firms' levels. This kind of organization gives firms the necessary flexibility to adjust their structures and to ensure a faster circulation of the information, in which ICT play a crucial role.

It is also important to stress that the fact that a firm carries out its control by objectives or result, which requires an important coordination, has a positive impact on the probability of ICT adoption. Organizational synergies are here confirmed by the positive sign of the coefficient of the variable "Belonging to a group". When a firm is a large and multi-plants firm, the adoption of ICT facilitates the internal coordination and communication. Indeed, the need of a high coordination between firms within a group contributes to increase the probability of ICT adoption by firms

Concerning the organization and its connection with the use of ICT by Catalan firms, we have found that the organizational structure of labor relations (the application of a control per objectives or results) do not have an influence on the intensity of use of these tools, but do have a positive effect on the equipment in ICT. This may mean that in an earlier stage of 
adoption, firms have not re-arranged the organization in a way to faster efficient usages. This requires more time and may explain why productivity is shortcut in short-run.

\section{Network effects}

We also observe that the degree of ICT adoption is higher for importing firms. This is explained by the fact that importation requires the automation of the relationship with providers and perhaps more information processing. This international effect is observed in all studies. We have found a significant and positive coefficient of the variable "importer firm".

The connectivity effect is also validated in our study. Indeed, an important result appears when analysing external links of a firm. External communication is measured by the number of customers and providers. The pressures by customers and providers to improve communication and to use specific software to manage this kind of relationships contribute to increase the probability of ICT adoption, as firms encourage their suppliers to adopt compatible technologies in order to coordinate their relationships, to improve their information processing capacity and to improve their reliability. This theoretical effect has been validated for Catalan firms in our estimate. Thus, we have found the more the number of customers and suppliers increases the higher is the degree of ICT adoption by firms.

Firms' networking structure results were on the opposite side to those of firm's size and productivity. It is remarkable the fact that those firms who are more connected with foreign markets ("importer firms") are those showing a higher probability of depth of ICT adoption. Therefore, it can be said that the promotion of net organizational structures leads to a positive and significant effect on a firm's willingness to show more advanced uses of digital technologies.

Another interesting result is the weak link between industry belonging and the probability of ICT adoption. Our results show that only in one out of three ICT equipment models we have specified (the General model) the coefficient is significant, with $p<0,05$, confirming the idea of the general diffusion of ICT among industries. However, in our General model, we have found some significant differences between industries, evidencing that ICT industry willingness to increase its digital capital stock is higher than the average probability for the rest of industries. But, differently to the determinants of ICT investment, the industrial approach plays here and important role. Our results show that ICT and digital content producers are also those firms showing a higher intensity of use of this kind of technologies than the rest of the industries in their production processes.

Nowadays, innovation is the main driver of change in business and in the whole economy. In an environment of globalization, knowledge and the development of capital value added become strongly important factors of competition. Consequently, in a knowledge-based economy, where coordination and communication intra and inter-firm is required, investment in digital technologies is consistent with business innovation.

The capability and willingness of a firm to innovate is another significant variable in the explanation of firms' investment in ICT equipment. In this sense, we have found a positive and significant effect from innovative firms (those that have innovated in the last two years), from those firms that are used to innovation by using digital technologies, and from cooperation to innovate. This last issue is particularly important in the case of small and 
medium size enterprises (SME's), which usually do not have a formal department devoted to Research and Development activities.

We can also confirm that those firms that have innovated during the last two years, and specially those whose innovation has been led by ICT uses, show more willingness to have higher levels of depth of digital technologies adoption. So, the results in table 4 indicate that cooperation and innovation has a statistically significant effect on the use of the ICT and especially the innovation, which has a significant coefficient at $1 \%$ level.

In this same context, one of the main advantages of innovation is the incentive that it gives to companies to become a part of networks of co-operation. Thus, and what is confirmed by the results of table 3 , it is noticed that the degree of co-operation of the firm with other companies or institutions (universities, research centers, public authorities...) has a positive impact on the diffusion of ICT. Therefore, we can conclude that innovation and firms' co-operation have a positive effect on ICT adoption by Catalan companies.

As an example of innovation in the process, we quote a firm, which adopts new online shop software. This may allow the firm to deliver its products to customers in a new way or to offer additional services, such as tracking orders online or getting immediate information about availability. This new process thus required an important use of digital technologies, because ICT make the innovation process more dynamic, but also more interactive and interdependent. What thus justifies the higher coefficient of the variable "Innovation process led by ICT use" in our results.

These unidirectional relationships we have found are consistent with the results available in the international literature, which evidence positive complementary effects from ICT investment, organizational change and the demand for skilled labour on the improvement of firms' efficiency (Bresnahan et al., 2000; Cristini et al., 2003).

The dynamic of uses may not follow the same patterns of the adoption of technologies. This lag between adoption and use is due to a required adjustment of the new technologies to the routines of firms. Our estimate verifies most of the effect for use dynamics.

Three main reasons describe the positive correlation between ICT uses and innovation for Catalan companies. Firstly, because ICT stimulate innovative dynamism in reducing partially the existing constrains to innovate and making interactions between the agents involved in the innovative process - those both inside and outside the company - more efficient. Secondly, ICT modify the nature of innovations and allow the development of more sophisticated and interdependent innovative processes. Thirdly, because the complexity of innovative processes induced by ICT means that their use can be considered a sustainable competitive advantage only if these technologies are used in an integrated structure with the available resources and capacities.

With regards to the influence of the cooperation effect, we observe that firms which cooperate with others institutions or firms, have a higher probability of using ICT than the others. One of the main positive effects of ICT usage, as an innovation tool is the incentive it represents for Catalan firms to build new cooperation networks or to make the existing ones more efficient. 
In this sense, from our results, it can be stated that there is a positive and significant relationship between ICT uses by firms, networking structure, workers' skills and profile, and innovation capabilities and background, as these are the main determinants of the intensity of uses of digital technologies.

\section{Concluding Remarks}

In this paper, we try to understand the main forces behind the ICT intra-firm diffusion process. For that, we analyse a representative sample of Catalan firms through a single year (2003) cross-section database. And propose an approach to modelling the determinants of ICT intra-firm diffusion by combining diffusion theories with complementarities approaches and technical choices perspectives. Our main contribution lies in the measurement and estimation of organizational network effects to explain the depth of digital technologies' adoption by firms.

In order to achieve consistent results and given the important difficulties to define a measure of digital uses within a firm, we propose a twofold measurement system: i) a first one that consider specific ICT tools (such as CRM, EIS or ERP) adopted by a firm (as they are specific and complex, we assume that a firm will only adopt them if an "appropriate" use has been planned before adoption); ii) and a second measure that relies on different business uses of digital technologies that have been declared by firms.

Our results confirm that inter-firm diffusion of ICT, estimated in our work with a general model of digital tools' adoption, can be identified as a previous step to depth of adoption in firms. Thus, inter-firm and intra-firm diffusion processes have different determinants, although they share some common traits based on the existence of complementary effects between digital technologies, innovation, organizational structure and workers skills within a firm.

On one hand, inter-firms diffusion of ICT mainly depends on the chance of obtaining scale economies by a firm and a firm's capability to reach to positive returns to its investment through efficiency levels have a positive. Thus, the effect of firms' size and productivity levels is confirmed here. However, ICT capital is characterised by representing general purpose technologies and by being complementary to some advanced organizational practices and to analytic, interactive and computing skills. These particular traits can explain why, differently to other industrial technologies, there is an important relationship between ICT adoption in firms and: i) decentralization of decision making processes, ii) human capital formation through the demand for managers with higher education attainment and the investment in workers' training programmes, and iii) firms' willingness to innovate, to use ICT as an innovation tool or mechanism, and to cooperate with other organization for innovating.

On the other hand, intra-firm diffusion of ICT is more related to firms' capability to improve their efficiency through digital business uses. This is the reason why complementing technological diffusion theories with organizational network complementarities and epidemic evolutionary models allow us to explain much better the main determinants of the depth of ICT adoption within forms. Empirically, these approaches can be identified in five critical variables: i) firms' networking organizational structure, ii) the demand for high qualified 
managers, iii) the existence of young workers, iv) the innovation background and v) the belonging to ICT industry.

We have also found a difference concerning some organization effects between inter-firm and intra-firm diffusion patterns. The recombination and the modification of the technologies were not optimal at the earlier stage of adoption. The study is based upon a questionnaire concluded in an earlier period of ICT diffusion in Catalonia; a new survey may reveal changes in these dynamics. Our study confirms the lag between adoption and usage of these technologies in the earlier stage of adoption.

\section{References}

D. Acemoglu and Newman F. A. (2002) 'The labor market and corporate structure' European Economic Review, Elsevier, 46(10), 1733-56, December.

C. Antonelli (2003) 'The economics of innovation, new technologies and structural change' London, Routledge.

T. B. Astebro (2004) 'Sunk costs and the depth and probability of technology adoption' Journal of Industrial Economics 52 (2004), 381-399.

G. Battisti and P. Stoneman (2003) 'Inter- and intra-firm effects in the diffusion of new process technology’ IResearch Policy, 32, 1641-1655.

G. Battisti and P. Stoneman (2005) 'The intra-firm diffusion of new process technology' International Journal of Industrial Organization 23, 1-22.

B. Bellon, A. Ben Youssef and Mhenni, H. (2006) 'Le maillon manquant entre adoption et usage des TIC dans les fonctions managériales des économies du sud méditerranéen' Revue Française de Gestion, 166, 173-189.

B. Bellon, A. Ben Youssef and Mhenni, H. (2007) 'Les capacités d'usage des technologies de l'information et de la communication dans les économies émergentes' Revue Tiers Monde, 192, 919-936.

A. Ben Youssef, W. Hadhri and H. Mhenni (2011), 'Intra-firm diffusion of innovation: Evidence from Tunisian SME's in matter of Information and Communication Technologies' Middle East Development Journal (MEDJ) (to appear).

I. Bertschek and H. Fryges (2002) 'The adoption of business-to-business e-commerce: empirical evidence for German companies' Discussion Paper No. 02-05, Centre for European Economic Research, Mannheim.

R. Bocquet and O. Brossard (2007) 'The variety of ICT adopters in the intra-firm diffusion process: Theoretical arguments and empirical evidence' Structural Change and Economic Dynamics, 18, 409-437.

T. Bresnahan, E. Brynjolfsson and L. Hitt (2002 a) 'Technology, Organization, and the Demand for Skilled Labor' The New Relationship: Human Capital in the American Corporation, M.M. Blair and T.A. Kochan, eds. Brookings Institution Press. 
T. Bresnahan, E. Brynjolfsson and L. Hitt (2002 b) 'Information Technology, Workplace Organization and the Demand for Skilled Labor: Firm-Level Evidence' The Quarterly Journal of Economics, 117(1), 339-376.

T. Bresnahan and M. Trajtenberg (1995) 'General purpose technologies: 'Engines of Growth' Journal of Econometrics, 65(1), 83-108.

E. Brousseau (1994) 'EDI and inter-firm relationships: toward a standardization of coordination process' Information Economics and Policy, 6, 319-347.

T. Bresnahan and L. Hitt (2003) 'Beyond computation: information technology, organizational transformation and business performance' Journal of Economic Perspectives $14,23-48$.

E. Caroli and J. Van Reenen (2001) 'Skill-Biased Organizational Change? Evidence From A Panel Of British And French Establishments' The Quarterly Journal of Economics, MIT Press, 116(4), 1449-1492, November.

W. Cohen and D. Levinthal (1989) 'Innovation and learning: the two faces of RandD' Economic Journal, Vol. 99: 569- 596.

A. Cristini, A. Gaj, S. Labory and R. Leoni (2003) 'Flat hierarchical structure, bundles of new work practices and firm performance' Rivista Italiana degli Economisti, 8(2), 313-341.

S. Davies (1979) 'The Diffusion of Process Technologies' Cambridge University Press, Cambridge.

M.E. Doms and T. Dunne (1998) 'Capital Adjustment Patterns in Manufacturing Plants' Review of Economic Dynamics, 1(2), 409-429, April.

T. Dunne (1994) 'Plant age and technology use in U.S. manufacturing industries' Rand Journal of Economics, 25, 488-499.

S. Fabiani, F. Schivardi and S. Trento (2005) 'ICT Adoption in Italian Manufacturing: Firm Level Evidence' Industrial and Corporate Change, 14(2), 225-249.

R. G. Fichman and C . F. Kemerer (1997) 'Object Technology and Reuse: Lessons from Early Adopters' IEEE Computer, 30(10), 47-59.

D. Foray (2004) 'The Economics of Knowledge' Cambridge, MA: MIT Press.

K. Foss, N. J. Foss and P. G. Klein (2007) 'Original and Derived Judgment: An Entrepreneurial Theory of Economic Organization’ Organization Studies, 28(12), 1893-1912.

C. Freeman and L. Soete (1997) 'The Economics of Industrial Innovation' third edition, MIT Press, Cambridge, Massachusetts.

D. Galliano and P. Roux (2006) 'Les inégalités spatiales dans l'usage des TIC : Le cas des firmes industrielles françaises’ Revue Economique, 57(6): 1449-1475. 
D. Galliano, P. Roux and M. Filippi (2001) 'Organisational and Spatial Determinants of ICT Adoption: The Case of French Industrial Firms' Environment and Planning, 33(9), 16431663 .

K. Gow (1996) 'Special report: Electronic commerce: Intranets vs. Notes' Computer World 30 (76).

W. H. Green (2000) 'Econometric Analysis' Fourth Edition, Prentice International Hall Edition.

N. Greenan (2003) 'Organizationnal change, technology, employment and skills: an empirical study of French manufacturing' Cambridge Journal of Economics, 27, 287-316.

H. Hollenstein (2004) 'The determinants of the adoption of ICT' Structural Change and Economics Dynamics 15: 315-342.

M. Huggett and S. Ospina (2001) 'Does productivity growth fall after the adoption of new technology?' Journal of Monetary Economics, Elsevier, 48(1), 173-195, August.

W Jorgenson Dale, S. Ho Mun and J. S. Kevin (2005) 'Information Technology and the American Growth Resurgence' Productivity, 3.

C. Karlsson (1995) 'Innovation adoption, innovation networks and agglomeration economies' In Bertuglia C.S., Fischer M.M., Preto G. (eds.), Technological change, economic development and space. Springer 184-206.

T. Lange, M. Ottens and A. Taylor (2000) 'SMEs and barriers to skills development: a Scottish perspective' Journal of Industrial Training, 24, 5-11.

K. Leduc (2006a) 'L'intégration des TlC dans les entreprises : quel impact sur leurs partenariats ? Une analyse sur des entreprises implantées au Luxembourg' Working Paper Département 'Entreprises' N²006-02.

K. Leduc (2006b) 'Les travailleurs âgés face aux TIC' EPS/INSTEAD Working Paper Département 'Entreprises' №2006-03.

D. I. Levine (1998) 'Working in the twenty-first century: policies for economic growth through training, opportunity, and education' Armonk, N.Y.: M.E. Sharpe.

P. Love, Z. Irani, C. Standing, C. Lin and J.M. Burn (2005) 'The Enigma of Evaluation: Benefits, Costs and Risks of IT in Australian Small-Medium-Sized Enterprises' Information and Management, 42(7), 947-964.

G. Maddala and A. Flores-Lagaunes (2001) 'Qualitative Response Models' in B. Baltagi, ed BALTAGI ED., A Companion to Theoretical Econometrics. Oxford: Blackwell.

P. Milgrom and J. Roberts (1992) 'Economics, Organization and Management' Englewood Cliffs: Printice-Hall International Edition 
A. Morgan, D. Colebourne and B. Thomas (2006) 'The Development of ICT Advisors for SME Business: An Innovative Approach’ Technovation, 26(8), 980-987.

M. Murphy (2002) 'Organisational Change and Firm Performance' STI Working Paper 2002/14.

OECD (2004) 'The Economic Impact of ICT, Measurement, Evidence and Implications' Paris: OECD.

P. Osterman (2000) 'Work Reorganization in an Era of Restructuring: Trends in Diffusion and Effects on Employee Welfare' Industrial and Labor Relations Review, 53, no. 2 (January, 2000), 176-96.

L. Raymond and G. Paré (1992) 'Measurement of information technology sophistication in small manufacturing businesses' Information Resources Management Journal. 5(2) 4-16.

E. M. Rogers (1995) 'Diffusion of Innovations' (fourth Ed.), New York, Free Press.

E. B. Swanson (1994) 'Information systems innovation among organizations' Management Science. 40(9), 1069-1092.

A. Thomas (2000) 'Econometric of the qualitative variables' Dunod, Paris.

J. Y. L. Thong (1999) 'An Integrated Model of Information Systems Adoption in Small Business’ Journal of Management Information Systems, 4(15), 187-214.

P. Windrum and P. De Berranger (2003) 'Factors affecting the adoption of intranets and extranets by SMEs: a UK study' Research Memorandum 2003-023, MERIT, Maastricht. 